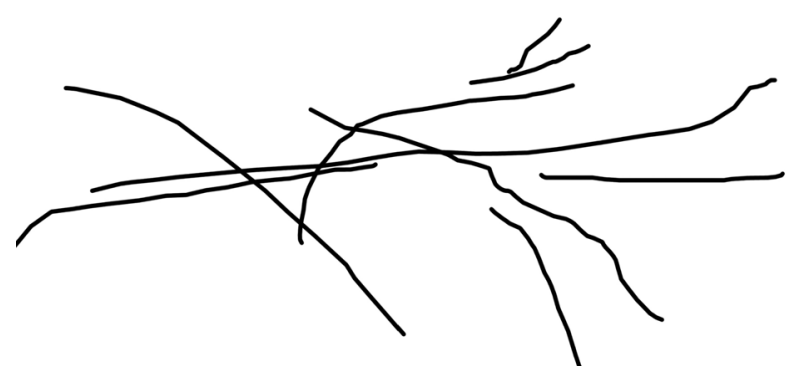

\title{
A participação da ANDES-SN" na CINAEM": o processo de transformação das escolas médicas brasileiras
}

A CINAEM (Comissão Interinstitucional Nacional de Avaliação do Ensino Médico) é um colegiado que reúne 11 entidades representativas dos professores universitários, da profissão médica, e de estudantes de medicina do país. Constituída há oito anos, a Comissão tem por objetivos: desenvolver metodologias alternativas ao projeto neoliberal de avaliação do ensino nas escolas médicas brasileiras; aplicar os instrumentos de avaliação em comum acordo com o coletivo das escolas médicas; identificar os problemas $e$ aspectos favoráveis e desfavoráveis que envolvam a formação médica no país; identificar os fatores facilitadores $e$ impeditivos para a construção de novo modelo de formação médica; formular e apresentar estratégias capazes de reforçar os fatores facilitadores $e$ de eliminar/neutralizar os fatores impeditivos do processo de mudança do modelo de formação das escolas; sistematizar, disseminar e divulgar os conhecimentos acumulados e os resultados obtidos com o desenvolvimento da avaliação $e$ do processo de transformação das escolas médicas por meio do potencial de mobilização social e capital político das entidades que compõem a Comissão e do coletivo das escolas médicas brasileiras. Nascida como um movimento de resistência $e$ oposição de entidades sindicais, científicas $e$ estudantis da área médica à política neoliberal de "ranqueamento" dos cursos de graduação do país, a partir da implementação impositiva do "provão", nesses oito anos de atividades a CINAEM tem desenvolvido seu trabalho no sentido de construir uma nova "consciência do ato de avaliar" por meio da ampliação da participação ativa de docentes e alunos no processo e da adesão das escolas médicas. A necessidade de se conhecer melhor o ensino médico no país, a falta de tradição acadêmica na sua avaliação $e$ a crise nacional do setor saúde foram marcos fundamentais para a formação da CINAEM. Buscava-se conhecer melhor as escolas médicas brasileiras e o ensino que estas ofereciam. Procurava-se constituir um movimento de envergadura nacional para discutir democraticamente o ensino $e$ a profissão médica com representantes de professores, alunos e da sociedade civil de todas as

* Associação Nacional dos Docentes do Ensino Superior - Sindicato Nacional.

** Comissão Interinstitucional Nacional de Avaliação do Ensino Médico. 
regiões do país.

No processo de constituição do movimento pelas instituições e entidades ficou definido que a CINAEM deve funcionar independente de governos e sob a coordenação da Associação Brasileira de Educação Médica ABEM, secretariada pelo Conselho Federal de Medicina e pela Associação Nacional dos Docentes do Ensino Superior - Sindicato Nacional - ANDES-SN, "tendo como princípios fundamentais e objetivos a qualidade do ensino médico e o aperfeiçoamento do sistema de saúde, binômio indispensável à boa formação profissional".

Enquanto pólo catalisador da mobilização social, a CINAEM foi o principal movimento de aglutinação de professores e estudantes na universidade brasileira, na última década, em torno da política de formação de recursos humanos em saúde. Outro ponto importante foi a incorporação coletiva dos conhecimentos técnicos e instrumentos desenvolvidos para a avaliação reconhecidamente de caráter científico, o que possibilitou a sua aplicação na maioria das escolas médicas do país, bem como o inequívoco salto de qualidade no processo de avaliação, se comparado àqueles até então desenvolvidos.

Nesse período, a Comissão desencadeou o processo de avaliação das escolas médicas em duas fases. A primeira, envolvendo 76 escolas, forneceu, por meio de extenso questionário, um rico arsenal de informações acerca da estrutura político-administrativa, infra-estrutura material e recursos humanos, além de informações acerca de modelo pedagógico, produção de pesquisas $e$ prestação de serviços à comunidade. A segunda fase do projeto aprofundou o processo avaliativo, trazendo informações mais precisas e em maior número. Caracterizou-se pelo entrecruzamento das informações de três estudos realizados em 48 escolas médicas: o estudo acerca do perfil do corpo docente e da estrutura econômicapolítica-administrativa das escolas, o estudo envolvendo conhecimentos e habilidades adquiridas pelos estudantes no final do processo de formação, e outro envolvendo a avaliação do modelo pedagógico na perspectiva do Planejamento Estratégico Situacional.

Com os resultados obtidos nestas duas fases, cada escola médica participante do projeto CINAEM dispõe, hoje, de um conhecimento detalhado da sua realidade, registrado em relatório individual. Por outro lado, o relatório geral do conjunto das escolas participantes permite visualizar a situação atual do ensino médico no país, possibilitando, a cada escola, situar o seu desempenho no contexto do conjunto das escolas estudadas.

Da análise global do relatório geral das escolas médicas pode-se depreender informações, dentre as quais destacam-se:

Informações relativas às conclusões na primeira fase do Projeto

1 A estrutura político-administrativa da maioria das escolas médicas é centralizada, pouco eficiente e pouco eficaz. A estrutura econômica-administrativa não tem autonomia, é pouco ágil e insuficiente frente às necessidades básicas das instituições. A infra-estrutura material é aquém da desejável e sucateada.

2 Os recursos humanos disponíveis são escassos, pouco preparados e com regime de trabalho insuficiente às necessidades do ensino médico.

$3 \mathrm{O}$ modelo pedagógico adotado nas escolas é anacrônico, fragmentado $e$ compartimentado.

4 As escolas têm um papel tímido quanto a produção de conhecimentos (pesquisa) $e$ prestação de serviços à comunidade (extensão). Como conseqüência, formam médicos inadequados às demandas sociais. 5 Entre todas as variáveis estudadas na primeira fase, os recursos humanos e o modelo pedagógico das escolas tiveram o maior poder de determinação na adequação do médico formado. Informações relativas às principais 
conclusões da segunda fase do projeto 1 Observou-se que a formação do corpo docente em nível de pós-graduação stricto sensu é rara entre os professores médicos; o regime de trabalho dominante é o de vinte horas (ou menos) semanais; as atividades de pesquisa $e$ administração são prerrogativas de poucos docentes; $e$ a produção acadêmica é discreta.

2 A remuneração da docência médica está abaixo da realidade do mercado de trabalho médico. Além disso, o processo de educação médica, estimado por meio da aquisição de bibliografias atualizadas, freqüência a cursos, congressos, estágios e outros eventos de caráter científico, é de participação restrita a uma minoria entre docentes médicos, em função do alto custo e da necessidade de afastamento das atividades relacionadas ao cotidiano da profissão médica.

3 A atividade da docência é uma atividade secundária no exercício profissional do médico que, na grande maioria, exerce outras atividades relacionadas ao trabalho profissional, e com maior remuneração do que a atividade acadêmica.

4 Com relação ao processo de formação instituído na escola médica, percebe-se que ocorre de forma predominante a transferência unidirecional e fragmentada de informações (mais teoria e menos prática), com profunda dicotomia entre os conhecimentos básicos e profissionalizantes. 5 As avaliações de aprendizagem são de caráter terminal, coercitivas, centradas na memória, sem contemplar as habilidades $e$ atitudes na aplicação do conhecimento. A gestão da escola médica aparece como centralizadora $e$ reprodutiva $e$ desempenhada por docentes formados na própria escola, sem formação específica para a função e satisfeitos com a estrutura vigente da instituição.

6 Com relação à aquisição de conhecimentos durante o processo de formação, os formandos demonstraram um crescimento cognitivo lento durante o período de graduação e um resultado final aquém do desejável.

7 Os resultados desta fase demonstram que a formação do docente em termos de pós graduação stricto sensu, bem como o regime de trabalho de quarenta horas e o regime de dedicação exclusiva, estiveram associados a um melhor desempenho do docente e este a um melhor crescimento cognitivo dos alunos. É importante salientar que o processo de avaliação empreitado pela CINAEM e pelo conjunto das escolas médicas brasileiras apresenta-se como claro contraponto às políticas nacionais para o ensino superior propostas pelo atual governo, as quais têm apontado para o desmonte do ensino público e sucateamento dos hospitais universitários e ambulatórios. Em função desta política são flagrantes os sinais de "desprofissionalização" do professor no sentido de descompromisso crescente da atividade relacionada a "docência" propriamente dita, junto às atividades de ensino na graduação, em detrimento de outras atividades de maior compensação financeira.

Mediante resultados que apontam para uma situação preocupante, de baixa qualidade na formação de médicos no país, torna-se claro o desejo de transformação da realidade por parte de estudantes, professores e dirigentes das escolas médicas. Os sinais da forte mobilização em torno das questões levantadas pela CINAEM têm sido observados em encontros e congressos de estudantes, encontros locais, regionais e nacionais das sociedades médicas e, principalmente, nos congressos da ABEM.

Nessa perspectiva surge, a partir do trabalho da equipe técnica assessora da CINAEM, a terceira fase do projeto, intitulada

"Transformando a Educação Médica Brasileira".

Nesta, o projeto se caracteriza pela implementação de mudanças estruturais por meio da intervenção participante nos cursos de medicina, sem perder de vista o contínuo processo de avaliação das escolas. Para sua viabilização estão sendo envidados esforços 
das entidades no sentido de levantar recursos junto às agências nacionais $e$ internacionais de fomento, sem, contudo, transigir da autonomia da CINAEM sobre a condução política do projeto. Cerca de 72 escolas médicas (de um total de 92) já manifestaram interesse em participar desta nova etapa.

A terceira fase é substancialmente diferente das anteriores. Enquanto as duas primeiras puderam ser conduzidas como projetos de pesquisa, porque tinham como objetivo o estabelecimento de um diagnóstico, a atual tem como questão central um amplo processo de mudanças que se situa no campo político-administrativo e institucional. $\mathrm{Ou}$ seja, é um projeto de base científica mas, também, uma ação política. Para que este processo seja alavancado em nível nacional faz-se necessária a articulação não só de atores internos à Universidade mas também de outros, principalmente junto àqueles que estão envolvidos no processo de mudança do modelo de prestação de serviços de saúde - o SUS - cujo desenvolvimento também não prescinde da ação articulada com a Universidade (no que tange a qualificação de recursos humanos, formulação de novos modelos de atenção, custos etc). Esta parceria é fundamental e estratégica para os dois setores e poderá ser geradora de força política e mobilização suficiente para impulsionar um amplo processo de mudanças do setor saúde no país.

PALAVRAS-CHAVE: Universidades; Brasil; transformação

180 Interface - Comunic, Saúde, Educ 5
A ANDES-SN tem atuado com marcante presença ao longo da história da CINAEM, por entender que o exemplo oferecido pelo movimento na área médica pode servir ao conjunto da universidade brasileira como um modelo, no qual a lógica da avaliação é voltada para a transformação e melhoria da qualidade do ensino superior no país e não para punição dos estudantes, "ranqueamento" das escolas ou para o simples cumprimento das exigências do mercado.

Outro bom exemplo a se espelhar no movimento organizado pela CINAEM é a forma pela qual se procura semear no meio acadêmico a cultura avaliativa, a partir do interesse inerente à Universidade e à própria sociedade em melhorar a qualidade do ensino superior, distinguindo-se pelo pleno exercício da democracia no interior do movimento, pela mobilização social (envolvendo o conjunto das entidades $e$ a comunidade acadêmica) e pela prática de solidariedade, respeito mútuo e autonomia das entidades que compõem o colegiado $e$ as escolas médicas brasileiras.

José Lúcio Martins Machado, $1^{\circ}$ Vice-Presidente da ANDES-SN Regional - São Paulo e secretário de Comunicação da CINAEM. Professor da Faculdade de Medicina de Botucatu Unesp.

Textos para referência

ARAÚJO, J.G.C. O novo ensino médico e a sociedade brasileira. Boletim ABEM, v.26, n.3, 1998.

BATISTA, N.A. O ensino médico e a cultura avaliativa. Boletim ABEM, v.26, n. 4, 1998.

BELACIANO, M.I. Considerações gerais a respeito do Projeto CINAEM: II Fase. 1998. p.2. (Mimeogr.)

CINAEM. Relatório geral de avaliação das escolas médicas brasileiras. 1996. 35p. (Mimeogr.) PICCINI, R. et al. Transformando a educação médica brasileira. Projeto CINAEM: III Fase. 1998. 86p. (Mimeogr.) 